Article

\title{
Screening Effective Antifungal Substances from the Bark and Leaves of Zanthoxylum avicennae by the Bioactivity-Guided Isolation Method
}

\author{
Yongtong Xiong ${ }^{1,2,+} \mathbb{C}$, Guan Huang ${ }^{1,2,+}$, Zongli Yao ${ }^{1,2}$, China Zhao ${ }^{1,2}$, Xiang Zhu ${ }^{1,2} \mathbb{D}$, \\ Qinglai $\mathrm{Wu}^{1,2, *}$, Xudong Zhou ${ }^{3, *}$ and Junkai $\mathrm{Li}^{1,2, *}$ \\ 1 School of Agriculture, Yangtze University, Jingzhou 434025, China; Xiongyongtong0124@163.com (Y.X.); \\ Huang0506@163.com (G.H.); y806032526@163.com (Z.Y.); zhaochina0623@163.com (C.Z.); \\ cjdxnxyzx@sina.com (X.Z.) \\ 2 Institute of Pesticides, Yangtze University, Jingzhou 434025, China \\ 3 TCM and Ethnomedicine Innovation \& Development Laboratory, School of Pharmacy, Hunan University of \\ Chinese Medicine, Changsha 410208, China \\ * Correspondence: wq1106@163.com (Q.W.); xudongzhou999@163.com (X.Z.); junkaili@sina.com (J.L.); \\ Tel.: +86-716-8066314 (Q.W.) \\ + Yongtong Xiong and Guan Huang contributed equally to this study. \\ Academic Editor: Maria Daglia \\ Received: 25 October 2019; Accepted: 18 November 2019; Published: 20 November 2019

\begin{abstract}
To find good antifungal substances by the bioactivity-guided isolation method, we tracked down the effective antifungal substances in the bark and leaves of Zanthoxylum avicennae, and isolated three antifungal compounds 1, 2, and 3. The structures were identified as xanthyletin, luvangetin, and avicennin by ${ }^{1} \mathrm{H}-\mathrm{NMR},{ }^{13} \mathrm{C}-\mathrm{NMR}$, and HRMS spectra. Particularly, compound $\mathbf{2}$ had several isomers, and the ${ }^{1} \mathrm{H}-\mathrm{NMR}$ spectra of $\mathbf{2}$ in different solvents showed a significant difference. To determine the stereo structure of $\mathbf{2}$, a single crystal was prepared and identified by X-ray diffraction as Luvangetin. Moreover, the difference of ${ }^{1} \mathrm{H}-\mathrm{NMR}$ data of 2 between in solvent dimethyl sulfoxide- $d_{6}$ (DMSO- $\left.d_{6}\right)$ and deuterated chloroform $\left(\mathrm{CDCl}_{3}\right)$, and other reported isomers were discussed for the first time. The bioassay results indicated that the three compounds 1,2 , and 3 displayed low to high antifungal activities against tested phytopathogenic fungi. In particular, all compounds 1, 2, and 3 showed excellent antifungal activities against Pyricularia oryzae and Z. avicennae, with the values of half maximal effective concentration $\left(\mathrm{EC}_{50}\right.$ ) ranging from 31 to $61 \mathrm{mg} / \mathrm{L}$, and compound 3 was also identified as a more potent inhibitor against Fusaium graminearum $\left(\mathrm{EC}_{50}=43.26 \pm 1.76 \mathrm{mg} / \mathrm{L}\right)$ compared with fungicide PCA (phenazine-1-carboxylic acid) $\left(\mathrm{EC}_{50}=52.34 \pm 1.53 \mathrm{mg} / \mathrm{L}\right)$. The results revealed that compounds 1, 2, and $\mathbf{3}$ were the main antifungal substances of $Z$. avicennae, and can be used as lead compounds of a fungicide, which has good development value and prospect.
\end{abstract}

Keywords: Zanthoxylum avicennae; bioactivity-guided isolation method; antifungal activity; lead compound; fungicide

\section{Introduction}

Zanthoxylum avicennae belongs to Rutaceae, and is mainly distributed around southern coastal area of China and parts of Southeast Asia, such as Hainan, Fujian, Guangxi, the Philippines, and Vietnam [1]. Z. avicennae has often been used to treat and relieve many illnesses, such as multi-phlegm, rheumatism, sore throat, jaundice, insect and snake bites, vomiting and diarrhea, repel Ascaris, and digestive system diseases in clinical and in traditional Chinese medicine [2-8]. Therefore, $Z$. avicennae deserves great research value and the bioactive substances from $Z$. avicennae have 
attracted researchers' attention. Further studies have shown that Z. avicennae mainly contains the compounds of triterpenes, steroids, alkaloids, amides, lignans, coumarins, flavonoids, volatile oils, and fatty acids [6,9-12], and many compounds have been proven to have various bioactivities, such as anti-cancer, antibacterial [13], antimildew activities [14], inhibitory activities against Plasmodium vivax [15], and 1,1-diphenyl-2-picrylhydrazyl (DPPH) free radical-scavenging activity [16].

In China, Z. avicennae is distributed abundantly; however, research on the antifungal activity of $Z$. avicennae is seldom reported. In order to develop and utilize this plant resource to the best advantage, and expand the antifungal application of $Z$. avicennae, we used the bioassay-guided isolation method to focus on exploring the antifungal compounds of $Z$. avicennae. The results provide a research basis and helpful clues for the discovery of novel antimicrobial agents.

\section{Results and Discussion}

In this study, $28.0 \mathrm{~g}$ of bark crude extract were obtained from $120.0 \mathrm{~g}$ of bark, and $45.0 \mathrm{~g}$ of leave crude extract were obtained from $170.0 \mathrm{~g}$ of leaves of $Z$. avicennae. The extraction yields were $23.3 \%$ and $26.5 \%$, respectively. Eight fractions $(\mathbf{A}-\mathbf{H})$ were isolated from the bark crude of Z. avicennae and four fractions (I-L) were isolated from the leave crude. By the bioassay-guided isolation method, three bioactive compounds 1, 2, and 3 were isolated from the fractions, and all compounds were identified by ${ }^{1} \mathrm{H}-\mathrm{NMR},{ }^{13} \mathrm{C}-\mathrm{NMR}$, and HRMS spectra (see details in Supplementary Materials). Detailed analysis indicated that compounds 1-3 were xanthyletin [17,18], luvangetin [19,20], and avicennin [21,22], respectively, as shown in Figure 1.

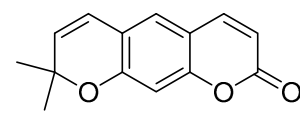

1

(Xanthyletin)

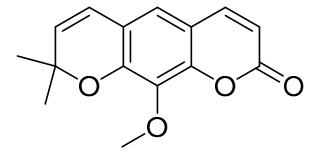

2

(Luvangetin)

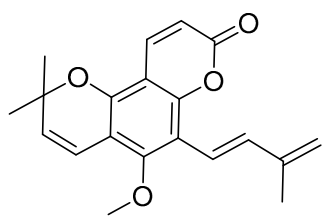

3

(Avicennin)

Figure 1. The structures of compounds 1-3.

However, we found that the NMR spectra of three compounds in solvent DMSO- $d_{6}$ and deuterated chloroform $\left(\mathrm{CDCl}_{3}\right)$ showed apparent differences. Particularly, the difference of the ${ }^{1} \mathrm{H}-\mathrm{NMR}$ spectra of compounds 1 and 2 were especially remarkable. In this research, the ${ }^{1} \mathrm{H}$ and ${ }^{13} \mathrm{C}-\mathrm{NMR}$ spectra of compounds 1, 2 and 3 in solvent DMSO- $d_{6}$, and the differences of ${ }^{1} \mathrm{H}-\mathrm{NMR}$ spectra in DMSO- $d_{6}$ and $\mathrm{CDCl}_{3}$ were reported for the first time, as shown in Table 1. Moreover, compound 2 had several natural isomers, such as luvangetin [19,20], alloxanthoxyletin [20], and xanthoxyletin [17,23], shown in Figure 2, and the ${ }^{1} \mathrm{H}-\mathrm{NMR}$ spectra of these compounds were very similar. Particularly, the ${ }^{1} \mathrm{H}-\mathrm{NMR}$ spectrum of compound 2 in DMSO- $d_{6}$ was almost consistent with the reported spectrum of xanthoxyletin in $\mathrm{CDCl}_{3}$ [17]. To determine the stereo structure of $\mathbf{2}$, a single crystal was prepared by slow evaporated in ethyl acetate at room temperature, and it was confirmed as luvangetin by X-ray diffraction, as shown in Figure 3.

Table 1. ${ }^{1} \mathrm{H}-\mathrm{NMR}$ data $(\mathrm{J}, \mathrm{Hz})$ of 2 in different deuterium solvents $(400 \mathrm{MHz}$ ) compared with the isomers reported by the literature.

\begin{tabular}{|c|c|c|c|c|c|}
\hline Location & $\stackrel{2}{\left.\stackrel{2}{(D M S O}-d_{6}\right)}$ & $\begin{array}{c}2 \\
\left(\mathrm{CDCl}_{3}\right)\end{array}$ & $\begin{array}{c}2 \\
\text { (In Ref.) }\end{array}$ & Alloxanthoxyletin & Xanthoxyletin \\
\hline $\mathrm{C}_{2}-\mathrm{H}$ & $7.92(\mathrm{~d}, 9.6,1 \mathrm{H})$ & $7.59(\mathrm{~d}, 9.6,1 \mathrm{H})$ & $7.57(\mathrm{~d}, 9.6,1 \mathrm{H})$ & $7.96(\mathrm{~d}, 10.0,1 \mathrm{H})$ & $7.85(\mathrm{~d}, 10.0,1 \mathrm{H})$ \\
\hline $\mathrm{C}_{3}-\mathrm{H}$ & $7.18(\mathrm{~s}, 1 \mathrm{H})$ & $6.85(\mathrm{~s}, 1 \mathrm{H})$ & $6.83(\mathrm{~s}, 1 \mathrm{H})$ & $6.36(\mathrm{~s}, 1 \mathrm{H})$ & $6.57(\mathrm{~s}, 1 \mathrm{H})$ \\
\hline $\mathrm{C}_{7}-\mathrm{H}$ & $6.29(\mathrm{~d}, 9.6,1 \mathrm{H})$ & $6.24(\mathrm{~d}, 9.6,1 \mathrm{H})$ & $6.24(\mathrm{~d}, 9.6 \mathrm{~Hz}, 1 \mathrm{H})$ & $6.16(\mathrm{~d}, 10.0,1 \mathrm{H})$ & $6.21(\mathrm{~d}, 10.0,1 \mathrm{H})$ \\
\hline $\mathrm{C}_{8}-\mathrm{H}$ & $5.88(\mathrm{~d}, 10.0,1 \mathrm{H})$ & $5.72(\mathrm{~d}, 10.0,1 \mathrm{H})$ & $5.71(\mathrm{~d}, 10.0,1 \mathrm{H})$ & $5.55(\mathrm{~d}, 10.0,1 \mathrm{H})$ & $5.71(\mathrm{~d}, 10.0,1 \mathrm{H})$ \\
\hline $\mathrm{C}_{1^{\prime}-\mathrm{H}}$ & $3.86(\mathrm{~s}, 3 \mathrm{H})$ & $3.99(\mathrm{~s}, 3 \mathrm{H})$ & $3.98(\mathrm{~s}, 3 \mathrm{H})$ & $3.87(\mathrm{~s}, 3 \mathrm{H})$ & $3.87(\mathrm{~s}, 3 \mathrm{H})$ \\
\hline
\end{tabular}


<smiles>COc1c2c(cc3ccc(=O)oc13)C=CC(C)(C)O2</smiles>

2

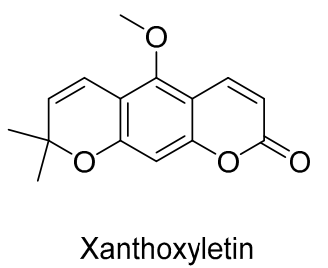<smiles>COc1cc2oc(=O)ccc2c2c1C=CC(C)(C)O2</smiles>

Alloxanthoxyletion

Figure 2. The natural isomers of 2.
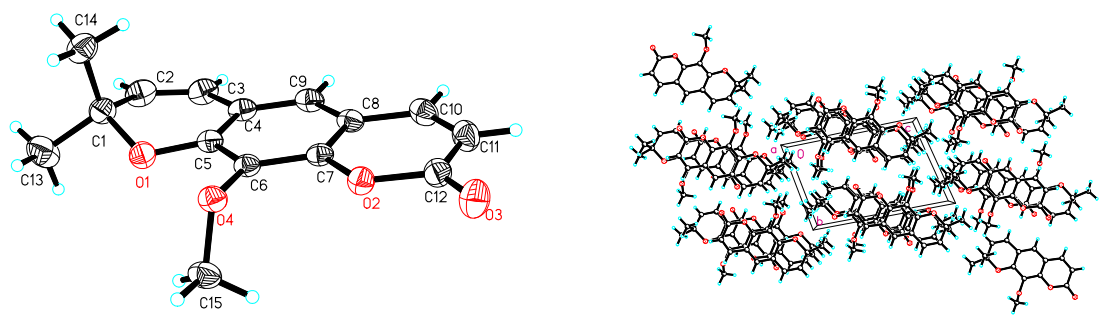

Figure 3. The X-ray crystal structure and crystal packing of 2.

According to the bioassay-guided isolation method, first, the crude extracts of Z. avicennae bark and leaves were screened for antifungal activities against six phytopathogenic fungi, such as Rhizoctonia solani, Fusaium graminearum, Altemaria solani, Fusarium oxysporum, Sclerotinia sclerotiorum, and Pyricularia oryzae, at the concentration of $500 \mathrm{mg} / \mathrm{L}$, as shown in Table 2 Considering the crude extract contained a large number of other substances, such as polysaccharides and proteins, and the contents of bioactive constituents were very low, the concentration of $500 \mathrm{mg} / \mathrm{L}$ was selected for screening to not miss the active ingredients. The results indicated that the crude extracts of $Z$. avicennae bark and leaves have certain antifungal activities against most tested phytopathogenic fungi. In particular, both the crude extracts of $Z$. avicennae bark and leaves showed moderate antifungal activities against $R$. solani. The inhibition rates were $61.89 \pm 2.81 \%$ and $56.07 \pm 1.76 \%$, respectively. The crude extracts of Z. avicennae bark also had moderate to high antifungal activities against $S$. sclerotiorum and P. oryae; the inhibition rates were $56.05 \pm 1.25 \%$ and $93.5 \pm 1.28 \%$, respectively.

Table 2. The in vitro antifungal activities of crude extract from bark and leaves of Zanthoxylum avicennae (Z. avicennae).

\begin{tabular}{ccccccc}
\hline \multirow{2}{*}{ Crude Extract * $^{*}$} & R. solani & F. graminearum & A. solani & F. oxysporum & S. sclerotiorum & P. oryae \\
\cline { 2 - 7 } & $61.89 \pm 2.81$ & $19.70 \pm 1.47$ & $2.14 \pm 0.82$ & $19.44 \pm 1.56$ & $56.05 \pm 1.25$ & $93.5 \pm 1.28$ \\
bark & $56.07 \pm 1.76$ & $0.00 \pm 0.00$ & $0.00 \pm 0.00$ & $45.15 \pm 0.00$ & $27.70 \pm 0.94$. & $15.50 \pm 0.82$ \\
\hline leaves & \multicolumn{7}{c}{${ }^{*}$ at the concentration of $500 \mathrm{mg} / \mathrm{L}}$.
\end{tabular}

Second, the crude extracts of Z. avicennae bark and leaves were separated by silica gel (200-300 mesh) column chromatography to obtain eight fractions (A-H) and four fractions (J-L), respectively. All fractions were tested for their antifungal activities against the same six phytopathogenic fungi at the concentration of $50 \mathrm{mg} / \mathrm{L}$, as shown in Table 3. The results showed that the fractions of Z. avicennae leaves had no antifungal activities to most phytopathogenic fungi. Only fraction I demonstrated activity against $P$. oryae and $F$. oxysporum with inhibition rates of $65.02 \pm 2.58 \%$ and $59.52 \pm 2.37 \%$, and fraction $\mathbf{J}$ against $P$. oryae with an inhibition rate of $66.46 \pm 2.43 \%$. The fractions $\mathbf{E}-\mathbf{H}$ of $Z$. avicennae bark also had no or very low antifungal activities to the tested phytopathogenic fungi, but the fractions A-D showed low to high antifungal activities. Particularly, fraction A showed the best antifungal activity against $P$. oryae with an inhibition rate of $96.05 \pm 0.81 \%$. Fraction B had good antifungal activities against R.solani and P. oryae with inhibition rates of $86.18 \pm 0.52 \%$ and $73.03 \pm 2.62 \%$, and fraction C indicated high antifungal activities against F.graminearum and P. oryae with inhibition rates of $87.89 \pm$ $0.82 \%$ and $82.78 \pm 0.94 \%$. The bioassay-guided results revealed that the antifungal substances mainly existed in fractions A, B and C. 
Table 3. The in vitro antifungal activities of the fractions isolated from Z. avicennae bark and leaves.

\begin{tabular}{|c|c|c|c|c|c|c|c|}
\hline \multirow{2}{*}{ Part } & \multirow{2}{*}{ Fractions * } & \multicolumn{6}{|c|}{ Inhibition Rate \% } \\
\hline & & R. solani & F. graminearum & A. solani & F. oxysporum & S. sclerotiorum & P. oryae \\
\hline \multirow{5}{*}{ bark } & $\mathrm{A}$ & $51.32 \pm 0.94$ & $22.05 \pm 0.82$ & $54.10 \pm 0.91$ & $24.26 \pm 1.25$ & $50.98 \pm 6.13$ & $96.05 \pm 0.81$ \\
\hline & $\mathrm{C}$ & $66.81 \pm 1.76$ & $87.89 \pm 0.82$ & $13.63 \pm 2.93$ & $16.45 \pm 0.81$ & $44.14 \pm 0.49$ & $82.78 \pm 0.97$ \\
\hline & $\mathrm{D}$ & $51.33 \pm 1.70$ & $26.77 \pm 2.87$ & 0 & $14.71 \pm 0.45$ & 0 & $46.71 \pm 2.45$ \\
\hline & $\mathrm{E}$ & 0 & 0 & $8.51 \pm 3.74$ & $7.94 \pm 1.25$ & 0 & $30.57 \pm 1.71$ \\
\hline & $\mathrm{H}$ & 0 & 0 & $3.55 \pm 3.77$ & 0 & $28.41 \pm 1.42$ & $13.38 \pm 0.86$ \\
\hline \multirow{4}{*}{ leaves } & I & $25.83 \pm 1.53$ & 0 & 0 & $65.02 \pm 2.58$ & $27.59 \pm 1.76$ & $59.52 \pm 2.37$ \\
\hline & $\mathrm{J}$ & $34.52 \pm 1.86$ & 0 & 0 & $8.22 \pm 1.72$ & $13.73 \pm 0.85$ & $66.46 \pm 2.43$ \\
\hline & $\mathrm{K}$ & 0 & 0 & $6.35 \pm 1.27$ & 0 & 0 & 0 \\
\hline & $\mathrm{L}$ & 0 & 0 & 0 & $5.38 \pm 0.82$ & $13.71 \pm 1.27$ & $8.28 \pm 0.81$ \\
\hline
\end{tabular}

Finally, fractions A, B, and C were separated and purified by silica gel (200-300 mesh) column chromatography again, and gained three purified compounds $\mathbf{1}, \mathbf{2}$, and $\mathbf{3}$, which were identified as xanthyletin, luvangetin, and avicennin by ${ }^{1} \mathrm{H}-\mathrm{NMR},{ }^{13} \mathrm{C}-\mathrm{NMR}$, and HRMS spectra. The results of the antifungal activities indicated that compounds xanthyletin, luvangetin, and avicennin also had good antifungal activities against F.graminearum, R.solani, and P. oryae, just like fractions A, B, and C, shown in Table 4. So, the $\mathrm{EC}_{50}$ values of xanthyletin against $P$. oryae, luvangetin against $R$. solani, and avicennin against $F$. graminearum and $P$. oryae were determined, as listed in Table 5 . The results showed that the antifungal activities of xanthyletin (1) and lcuvangetin (2) against $P$. oryae were slightly lower than PCA $(29.30 \pm 1.89 \mathrm{mg} / \mathrm{L})$, with $\mathrm{EC}_{50}$ values of $31.56 \pm 1.86$ and $35.89 \pm 1.64 \mathrm{mg} / \mathrm{L}$, respectively. Noteworthily, avicennin (3) showed higher antifungal activity against $F$. graminearum, with $\mathrm{EC}_{50}$ values of $43.26 \pm 1.76 \mathrm{mg} / \mathrm{L}$, than PCA $(52.34 \pm 1.53 \mathrm{mg} / \mathrm{L})$. The results revealed that xanthyletin, luvangetin, and avicennin are the main antifungal substances of $Z$. avicennae.

Table 4. The in vitro antifungal activities of compounds 1-3.

\begin{tabular}{ccccccc}
\hline \multirow{2}{*}{ Compound } & \multicolumn{7}{c}{ Inhibition Rate $\%$} \\
\cline { 2 - 7 } & R. solani & F. graminearum & A. solani & F. oxysporum & S. sclerotiorum & P. oryae \\
\hline $\mathbf{1}$ & $57.62 \pm 1.36$ & $31.80 \pm 2.15$ & $63.83 \pm 0.56$ & $26.28 \pm 0.93$ & $63.03 \pm 0.65$ & $98.32 \pm 1.67$ \\
$\mathbf{2}$ & $88.23 \pm 1.05$ & $16.86 \pm 1.57$ & $33.43 \pm 0.85$ & $38.61 \pm 1.93$ & $45.25 \pm 2.72$ & $75.87 \pm 0.86$ \\
$\mathbf{3}$ & $69.38 \pm 2.32$ & $89.03 \pm 1.74$ & $13.36 \pm 2.65$ & $17.67 \pm 1.56$ & $52.35 \pm 1.78$ & $86.06 \pm 1.81$ \\
PCA & $97.65 \pm 1.26$ & $48.78 \pm 1.64$ & $74.65 \pm 0.82$ & $52.08 \pm 1.23$ & $87.86 \pm 0.52$ & $87.59 \pm 0.65$ \\
\hline \multicolumn{7}{c}{${ }^{*}$ at the concentration of 50 $\mathrm{mg} / \mathrm{L}}$.
\end{tabular}

Table 5. The half maximal effective concentration $\left(\mathrm{EC}_{50}\right)$ values $(\mathrm{mg} / \mathrm{L})$ of compounds $1-3$.

\begin{tabular}{cccc}
\hline Compounds & R. solani & F. graminearum & P. oryae \\
\hline $\mathbf{1}$ & $49.10 \pm 1.03$ & $117.21 \pm 0.93$ & $31.56 \pm 1.86$ \\
$\mathbf{2}$ & $80.18 \pm 2.65$ & $134.26 \pm 1.19$ & $35.89 \pm 1.64$ \\
$\mathbf{3}$ & $40.58 \pm 2.59$ & $43.26 \pm 1.76$ & $61.62 \pm 2.12$ \\
PCA & $23.21 \pm 2.23$ & $52.34 \pm 1.53$ & $29.30 \pm 1.89$ \\
\hline
\end{tabular}

\section{Materials and Methods}

Chemicals and solvents were purchased from commercial suppliers in China and were used without further purification. Solvents and reagents were abbreviated as follows: Menthol $\left(\mathrm{CH}_{3} \mathrm{OH}\right)$, chloroform $\left(\mathrm{CHCl}_{3}\right)$, petroleum ether, dichloromethane (DCM), ethyl acetate (EtOAc), and sodium sulfate $\left(\mathrm{Na}_{2} \mathrm{SO}_{4}\right)$. All fungi were obtained from the School of Agricultural, Yangtze University $(\mathrm{CN})$. The melting points were determined on a WRR melting point apparatus (Shanghai Jingke Industrial Co. Ltd., Shanghai, China) and modified. Thin-layer chromatography (TLC) was performed on silica gel 60 F254 (Qingdao Marine Chemical Ltd., Qingdao, China). Column chromatography (CC) was performed over silica gel (200-300 mesh, Qingdao Marine Chemical Ltd., Qingdao, China). ${ }^{1} \mathrm{H}$ and 
${ }^{13} \mathrm{C}-\mathrm{NMR}$ spectrum were recorded in $\mathrm{CDCl}_{3}$ or DMSO- $d_{6}$ solution on a Bruker $400 \mathrm{MHz}$ spectrometer (Bruker Co., Fällanden, Switzerland), using tetramethyl silane (TMS) as an internal standard, and chemical shift values $(\delta)$ are given in parts per million (ppm). The following abbreviations were used to designate chemical shift multiplicities: $s=$ singlet, $d=$ doublet, $t=$ triplet, $q=$ quartet, $m=$ multiple. MS data were obtained using an APEX IV Fourier-Transform Mass Spectrometry (Bruker Daltonics, Billerica, MA, USA).

\subsection{Plant Material}

The bark and leaves of Z. avicennae were collected from Minlishan Mountain, Hezhou, China, and dried at room temperature $\left(25^{\circ} \mathrm{C}\right)$, then pulverized by plant grinder, and kept sealed in a dark place for later use.

\subsection{Extraction and Isolation}

In total, $120.0 \mathrm{~g}$ of bark powder were extracted with $400 \mathrm{~mL}$ of $\mathrm{MeOH}$ at room temperature for 2 days, and then the extract liquid was filtered and collected. The filter cake was repeatedly treated in the same way another two times, and combined three filtrates. In total, $170.0 \mathrm{~g}$ of leave powder of $Z$. avicennae were treated in the same way. The extracted solution was freeze-dried at $-50{ }^{\circ} \mathrm{C}$ to obtain the crude extract, and the extraction yield was calculated. The crude extracts of Z. avicennae leaves and bark were 45.0 and $28.0 \mathrm{~g}$, respectively, and the extraction yields were $26.5 \%$ and $23.3 \%$, respectively.

The crude extract of Z. avicennae bark (25.0 g) was applied to silica gel (200-300 mesh) column chromatography, and eluted with a petroleum ether (PE)/ethyl acetate (EA) and ethyl acetate $(\mathrm{EA}) /$ methanol $(\mathrm{MeOH})$ gradient system $(\mathrm{PE} / \mathrm{EA}=10: 0, \mathrm{PE} / \mathrm{EA}=8: 1, \mathrm{PE} / \mathrm{EA}=6: 1, \mathrm{PE} / \mathrm{EA}=4: 1$, $\mathrm{PE} / \mathrm{EA}=2: 1, \mathrm{EA} / \mathrm{MeOH}=1: 1, \mathrm{EA} / \mathrm{MeOH}=0: 1)$ to give eight fractions $(\mathbf{A}-\mathbf{H})$. The crude extract of $\mathrm{Z}$. avicennae leaves (40.0 g) was treated by a similar procedure to give four fractions (I-L). By the bioassay-guided isolation method, all fractions were tested for their antifungal activities and highly active ones were screened (A, B, and $\mathbf{C})$. Then, fraction $\mathbf{A}$ was separated and purified by silica gel (300-400 mesh) column chromatography, which was eluted with a $\mathrm{CHCl}_{3} / \mathrm{MeOH}$ (90:100-80:20) gradient system to get purified compound 1. Fraction $\mathbf{B}$ was recrystallized three times by chloroform at $-4{ }^{\circ} \mathrm{C}$ to give purified compound 2. Fraction $\mathrm{C}$ was separated and purified by silica gel (300-400 mesh) column chromatography (eluted with $\mathrm{CHCl}_{3} / \mathrm{MeOH}$ (100:0-80:20) gradient system) and Waters Breeze ${ }^{\mathrm{TM}}$ $2 \mathrm{HPLC}\left(80 \% \mathrm{MeOH} / \mathrm{H}_{2} \mathrm{O}\right.$, flow rate $\left.20 \mathrm{~mL} / \mathrm{min}\right)$ to obtain purified compound 3.

\subsection{Primary Fungicidal activities}

The primary fungicidal activities of all crude extracts, fractions, and purified compounds were tested against six phytopathogenic fungi (Rhizoctonia solani, Fusaium graminearum, Altemaria solani, Fusarium oxysporum, Sclerotinia sclerotiorum, and Pyricularia oryzae) by the mycelium growth rate isolation method [23], in which the concentration of crude extracts was $500 \mathrm{mg} / \mathrm{L}$ and the concentration of fractions and compounds was $50 \mathrm{mg} / \mathrm{L}$. The commercial fungicide Shenqinbactin (PCA) was assessed as positive controls at the concentration of $50 \mathrm{mg} / \mathrm{L}$. Each treatment was repeated three times. When the mycelia of CK grew to three quarters of the area of the diameter, it was measured by the cross isolation method [24,25], and the inhibition ratio was calculated by Equation (1):

$$
\text { Relative inhibition ratio }(\%)=[(\mathrm{CK}-\mathrm{PT}) /(\mathrm{CK}-6 \mathrm{~mm})] \times 100 \%
$$

where $\mathrm{CK}$ is the extended diameter of the circle mycelium during the negative control and PT is the extended diameter of the circle mycelium during experiment.

\subsection{EC $_{50}$ Value of Fungicidal Activities}

The $\mathrm{EC}_{50}$ values of the purified compounds obtained by the bioassay-guided isolation method were determined, and the final concentrations of all compounds in medium were 200, 150, 100, 50, 25, 
and $12.5 \mathrm{mg} / \mathrm{L}$. The isolation method of inoculating phytopathogenic fungi cakes and circle mycelium measurement was equal to the isolation method for testing the primary antifungal activities. All fungicidal activities were evaluated by statistical analysis. All statistical analysis was performed using EXCEL 2010, software (Microsoft, Redmond, WA, USA). The log dose-response curves allowed determination of the $\mathrm{EC}_{50}$ for the fungi bioassay according to probit analysis. The $95 \%$ confidence limits for the range of $\mathrm{EC}_{50}$ values were determined by the least-square regression analysis of the relative growth rate (\% control) against the logarithm of the compound concentration.

\section{Conclusions}

Z. avicennae, which has extensive pharmacological activities, was used as experimental material. The crude extracts of $Z$. avicennae bark and leaves were extracted by a cold soaking isolation method. By the bioassay-guided isolation method, we found that antifungal substances mainly exist in the bark of Z. avicennae, and three antifungal fractions $\mathbf{A}, \mathbf{B}$, and $\mathbf{C}$ were identified. Further separation and purification of fractions $\mathbf{A}, \mathbf{B}$, and $\mathbf{C}$ led to three purified compounds 1-3, which were identified as xanthyletin, luvangetin, and avicennin by ${ }^{1} \mathrm{H}-\mathrm{NMR},{ }^{13} \mathrm{C}-\mathrm{NMR}$, and HRMS spectra. The bioactivities of compounds 1-3 indicated that the three compounds had excellent antifungal activities against $F$. graminearum, $R$. solani, and P. oryae. In particular, xanthyletin and avicennin showed slightly lower antifungal activities against $P$. oryae than PCA $(29.30 \pm 1.89 \mathrm{mg} / \mathrm{L})$, with $\mathrm{EC}_{50}$ values of $31.56 \pm 1.86$ and $35.89 \pm 1.64 \mathrm{mg} / \mathrm{L}$, respectively. Avicennin showed higher antifungal activities against $F$. graminearum than PCA $(52.34 \pm 1.53 \mathrm{mg} / \mathrm{L})$, with an $\mathrm{EC}_{50}$ value of $43.26 \pm 1.76 \mathrm{mg} / \mathrm{L}$. So, compounds $1-3$ can be confirmed as the main antifungal substances of Z. avicennae, and can be used as lead compounds of a fungicide, which has good development value and prospect.

Supplementary Materials: The Supplementary Materials of ${ }^{1} \mathrm{H},{ }^{13} \mathrm{C}$ NMR and HRMS Spectra are available online.

Author Contributions: Q.W. and X.Z. (Xudong Zhou) performed the spectral analysis and structure determination; Y.X. and G.H. performed the extraction and isolation; G.H. and Z.Y. conceived and designed the microbiological experiments, Y.X. and C.Z. performed the antibacterial assay; J.L. contributed reagents and analysis tools; Q.W. and X.Z. (Xudong Zhou) conceived and designed the experiments; Q.W. and Z.Y. wrote the paper; X.Z. (Xiang $\mathrm{Zhu}$ ) reviewed and edited the paper. All authors reviewed the manuscript.

Funding: This research received no external funding.

Acknowledgments: This work was supported by Basic Science Research Program (31672069) through the Natural Science Foundation of China.

Conflicts of Interest: The authors declare no conflict of interest. The founding sponsors had no role in the design of the study; in the collection, analyses, or interpretation of data; in the writing of the manuscript, and in the decision to publish the results.

\section{References}

1. Cho, J.Y.; Hwang, T.L.; Chang, T.H.; Lim, Y.P.; Sung, P.J.; Lee, T.H.; Chen, J.J. New coumarins and anti-inflammatory constituents from Zanthoxylum avicennae. Food Chem. 2012, 135, 17-23. [CrossRef]

2. Liu, X.C.; Liu, Q.Y.; Zhou, L.; Liu, Q.R.; Liu, Z.L. Chemical Composition of Zanthoxylum avicennae Essential Oil and its Larvicidal Activity on Aedes albopictus Skuse. Trop. J. Pharm. Res. 2014, 13, 399-404. [CrossRef]

3. Trung, H.D.; Thang, T.D.; Khoi, N.K.; Dai, D.N.; Ogunwande, I.A. Chemical Constituents of Essential Oils from the Leaf, Flower and Fruit of Zanthoxylum Avicenna (Lam.) DC. (Rutaceae) from Vietnam. J. Essent. Oil Bear. Plants. 2016, 19, 1019-1024. [CrossRef]

4. Guo, T.; Tang, X.F.; Zhang, J.B.; Wei, J.Q.; Wang, Y.; Li, Y.H.; Zhang, Z. Chemical Constituents from the Root and Stem of Zanthoxylum avicennae. Appl. Mech. Mater. 2014, 618, 426-430. [CrossRef]

5. Xie, Z.; Huang, X. Dictionary of Traditional Chinese Medicine; Commercial Press: Hong Kong, China, 1985; pp. 175-181.

6. Wang, Y.; Wang, Z. Recent progress in bioactive fractions from plants of Zauthoxylum, L. Chin. Trad. Herb. Dru. 2002, 33, 666-670.

7. Perry, L.M.; Metzger, J. Medicinal Plants of East and Southeast Asia: Attributed Properties and Uses; MIT Press: Boston, MA, USA, 1980; Volume 33, p. 258. 
8. Xiong, Q.B.; Shi, D.W. Morphological and histological studies of Chinese raditional drug "hua jiao" (Pericarpium zanthoxyli) and its allied drugs. Acts. Pharm. Sin. 1991, 26, 938-947.

9. Liu, S.L.; Wei, L.X.; Wang, D.; Gao, C.Y. Studies on the chemical constituents from the peel of Zanthoxylum schinifolium Sieb et Zucc. Yao Xue Xue Bao = Acta Pharmaceutica Sinica 1991, 26, 836-840.

10. Wu, S.J.; Chen, I.S. Alkaloids from Zanthoxylum simulans. Phytochemistry. 1993, 34, 1659-1661.

11. Zheng, N.N.; Yang, S.X.; Zhou, H.; Yuan, K. Chemical fractions and bioactivities of Zanthoxylum avicennae. Chin. Tradit. Herbal. Drugs. 2015, 46, 189-193.

12. Sandjo, L.P.; Kuete, V.; Tchangna, R.S.; Efferth, T.; Ngadjui, B.T. Cytotoxic benzophenanthridine and furoquinoline alkaloids from Zarrthoxylum buesgenii (Rutaceae). Chem. Cent. J. 2014, 8, 1-5. [CrossRef]

13. Wang, H.S.; Yao, O.S.; Pan, Y.M.; Chen, Z.F. Antibacterial acitvity and compounds of the essential oil of Zanthoxylum nitidum var.fastuosum. Nat. Prod. Res. 2006, 18, 251-253.

14. Chen, J.; Chung, C.; Hwang, T.; Chen, J. Amides and Benzenoids from Zanthoxylum ailanthoides with Inhibitory Activity on Superoxide Generation and Elastase Release by Neutrophils. Planta Med. 2009, 75, 107-110. [CrossRef]

15. Samir, A.R.; Gazi, N.N.S.; Charles, L.B.; Mahmoud, A.E.; Jannie, P.J.M.; Daneel, F. Syncarpamide, a newantiplasmodial(+)-norepine-phrine derivative from Zanthoxylum syncarpum. J. Nat. Prod. 2004, 67, 88.

16. Abdul, S.B.; Dilfaraz, K. New prenylated carbazole alkaloids from Zanthoxylum armatum. J. Asian Nat. Prod. Res. 2014, 16, 1126-1131.

17. Ju, Y.; Still, C.C.; Sacalis, J.N.; Li, J.; Ho, C.-T. Cytotoxic coumarins and lignans from extracts of the northern prickly ash (Zanthoxylum americanum). Phytother. Res. 2001, 15, 441-443. [CrossRef]

18. Bissim, S.M.; Kenmogne, S.B.; Tcho, A.T.; Lateef, M.; Ahmed, A.; Happi, E.N.; Wansi, J.D.; Ali, M.S.; Waffo, A.F.K. Bioactive acridone alkaloids and their derivatives from Citrus aurantium (Rutaceae). Phytochem. Lett. 2019, 29, 148-153. [CrossRef]

19. Chen, J.-J.; Wang, T.-Y.; Hwang, T.-L. Neolignans, a Coumarinolignan, Lignan Derivatives, and a Chromene: Anti-inflammatory Constituents fromZanthoxylum avicennae. J. Nat. Prod. 2008, 71, 212-217. [CrossRef]

20. Bai, G.; Xu, J.; Cao, X.-L.; Pei, H. Preparative Separation of Luvangetin from Zanthoxylum Ailanthoides Sieb. \& Zucc. by Centrifugal Partition Chromatography. J. Liq. Chromatogr. Relat. Technol. 2014, 37, 1819-1826.

21. Eliana, E.D.; Gilsane, L.V.P.; Amélia, T.H. Constituents of Zanthoxylum rugosum St.-Hil \& Tul. Biochem. Syst. Ecol. 2000, 28, 275-277.

22. Chen, J.-J.; Yang, C.-K.; Kuo, Y.-H.; Hwang, T.-L.; Kuo, W.-L.; Lim, Y.-P.; Sung, P.-J.; Chang, T.-H.; Cheng, M.-J. New Coumarin Derivatives and Other Constituents from the Stem Bark of Zanthoxylum avicennae: Effects on Neutrophil Pro-Inflammatory Responses. Int. J. Mol. Sci. 2015, 16, 9719-9731. [CrossRef]

23. Bell, J.C.; Bridge, W.; Robertson, A. Constituents of the bark of Zanthoxylum americanum(mill). Part IV. J. Chem. Soc. 1937, 319, 1542-1545. [CrossRef]

24. Zhu, X.; Zhang, M.; Yu, L.; Xu, Z.; Yang, D.; Du, X.; Wu, Q.; Li, J. Synthesis and bioactivities of diamide derivatives containing a phenazine-1-carboxamide scaffold. Nat. Prod. Res. 2018, 33, 2453-2460. [CrossRef] [PubMed]

25. Yu, L.H.; Huang, D.; Zhu, X.; Zhang, M.; Yao, Z.L.; Wu, Q.L.; Xu, Z.H.; Li, J.K. Design, synthesis, phloem mobility, and bioactivities of a series of phenazine-1-carboxylic acid-amino acid conjugates. Molecules 2018, 23, 2139. [CrossRef] [PubMed]

Sample Availability: Samples of the compounds are available from the authors. 